\title{
Insect population trends and the IUCN Red List process
}

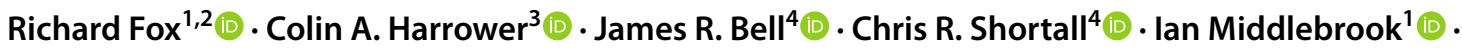 \\ Robert J. Wilson ${ }^{2,5}$
}

Received: 2 October 2018 / Accepted: 10 December 2018 / Published online: 19 December 2018

(c) The Author(s) 2018

\begin{abstract}
Reliable assessment of extinction risk is a key factor in the preparation of Red Lists and in prioritizing biodiversity conservation. Temporal population trends can provide important evidence for such assessments, but imperfect sampling (observation errors) and short-term stochastic variation in population levels caused by environmental variability (process errors) can reduce the reliability of trends and lead to incorrect quantification of extinction risk. The assessment of insect taxa is likely to be particularly prone to these problems, due to the highly dynamic nature of many insect populations, driven by short life-cycles and sensitivity to environmental factors such as the weather. Using long-term United Kingdom monitoring data for 54 butterfly and 431 macro-moth species, we demonstrate the impact of insect population variability on the assessment of extinction risk using the International Union for Conservation of Nature (IUCN) Red List Criterion A (reduction in population size over the last 10 years). For both taxa, varying the start year of the 10-year population trend had a substantial effect on whether particular species met Red List thresholds and on the overall number of species assessed as threatened. We conclude that for these insect taxa strict application of the 10-year rule produces Red List classifications that are unacceptably biased by the start year. Use of long-term trends with adjustment based on species performance over the last decade may offer a pragmatic solution to this problem. We call for further IUCN guidance for practitioners undertaking Red List assessments of taxa with populations that have high temporal variability.
\end{abstract}

Keywords Extinction risk $\cdot$ Threatened species $\cdot$ Biodiversity conservation $\cdot$ Monitoring $\cdot$ Butterflies $\cdot$ Moths

Electronic supplementary material The online version of this article (https://doi.org/10.1007/s10841-018-0117-1) contains supplementary material, which is available to authorized users.

Richard Fox

rf382@exeter.ac.uk

1 Butterfly Conservation, Manor Yard, East Lulworth, Wareham, Dorset BH20 5QP, UK

2 Biosciences, College of Life and Environmental Sciences, University of Exeter, Prince of Wales Road, Exeter EX4 4PS, UK

3 NERC Centre for Ecology \& Hydrology, Maclean Building, Benson Lane, Wallingford, Oxfordshire OX10 8BB, UK

4 Rothamsted Insect Survey, Rothamsted Research, Harpenden AL5 2JQ, UK

5 National Museum of Natural Sciences (MNCN-CSIC), 28006 Madrid, Spain

\section{Introduction}

Biodiversity conservation practitioners rely on robust assessments of extinction risk (at global, regional, national and even local scales) to prioritise the use of limited resources. The Red List process developed by the International Union for Conservation of Nature (IUCN) plays an important role both as the global standard for extinction risk assessment (Miller et al. 2007; Mace et al. 2008) and, indirectly, in catalysing conservation activity. The Red List process itself is solely an objective, quantitative assessment of threat across taxa. Nevertheless, by providing a key input into prioritisation decisions made by practitioners and as a consequence of increased public and political support stemming from the credibility and reputation of the process, Red Lists are frequently a starting point for the development of conservation initiatives (Rodrigues et al. 2006; Hoffmann et al. 2008; Azam et al. 2016).

The IUCN process utilises criteria with quantitative thresholds based on population and distribution size and 
rate of decline in order to classify taxa into Red List threat categories (IUCN 2001). The development, application and misuse of these criteria have been documented (Akçakaya et al. 2006; Mace et al. 2008; Collen et al. 2016), as have the wider problems of applying them to insects and other invertebrates due to data constraints (e.g. Cardoso et al. 2011; van Swaay et al. 2011; Azam et al. 2016). Criterion A "Reduction in population size" depends solely on measures of population decline over a (potentially short) time-period of the most recent 10 years or three generations, whichever is longer, hereafter referred to as the " 10 -year rule" for simplicity. Thus widespread and common species, with large population sizes and ranges, can qualify as being threatened with extinction on Red Lists if they are undergoing rapid decline. Criterion A is justified because even large populations would eventually be driven to extinction by continuing decline (Mace et al. 2008), especially as other negative feedback loops may come into play at low population densities (e.g. Allee effects, genetic inbreeding), but also because the reduction in abundance of common and widespread species may be of particular significance to ecosystem structure and functioning (Gaston and Fuller 2008; Winfree et al. 2015).

However, the reliable measurement of species population trends that indicate extinction risk (and are being driven by anthropogenic processes such as habitat loss or climate change) for use in Red List Criterion A is made difficult by imperfect sampling (observation errors) and short-term stochastic variation in population levels caused by environmental variability (process errors) (Connors et al. 2014). Inaccurate detection of underlying species population trends can result in incorrect Red List classification (false positives i.e. incorrectly classifying a species as threatened and false negatives i.e. failing to classify a species that should be listed as threatened).

Investigations, using both empirical and simulated data, show that as process errors (and observation errors) increase, the reliable detection of population declines decreases across a range of different statistical techniques (Wilson et al. 2011; McCain et al. 2016). Trends assessed over short time periods, such as those required under the IUCN 10-year rule, are particularly sensitive to process errors, resulting in high levels of false positive and false negative species assessments (Connors et al. 2014; d'Eon-Eggertson et al. 2015). Concern has also been raised over the fundamental assumption that short-term declines are reliable predictors of ongoing decline (and, therefore, extinction risk) and authors have regularly advocated the use of long-term population data, where available, to improve the accuracy of extinction risk assessment (Dunn 2002; Porszt et al. 2012; Keith et al. 2015; White 2018). These findings undermine confidence in the classification of extinction risk using Criterion A in its current form (White 2018). However, these studies are based almost exclusively on vertebrate examples, where biological traits (e.g. generation times, population growth rates) and specific environmental drivers (e.g. human exploitation) may differ markedly from those of insects. Indeed, Connors et al. (2014) predict that the lowest rates of false-positive and false-negative classification errors under IUCN Red List Criterion A will occur for large-bodied, long-lived animal species.

These findings do not bode well for the application of Criterion A to insects. Most insect species have very short generation times ( $\leq 1$ year), meaning that the 10-year rule is applied as a 10-year population trend over the most recent 10 years. By comparison, the same rule applied to longlived vertebrates would see trends measured over longer time periods equating to three generations of the species concerned. In addition, the poikilothermic and ectothermic physiology of many insects results in climatic sensitivity that can drive large fluctuations in population size from generation to generation, particularly near altitudinal or latitudinal range margins (Oliver et al. 2014). Short-term climatic variation is a principal driver of inter-annual population change in UK butterflies and moths (Roy et al. 2001; Oliver et al. 2015; Palmer et al. 2017), alongside density dependence (Mills et al. 2017).

Due to anticipated high levels of process error (as well as potential observation error), 10-year population trends of insects may not be sufficiently reliable to enable the accurate classification of extinction risk in the Red List process, but rather reflect spurious responses to short-term environmental stochasticity. Thus, Red List classifications based on such trends are likely to be strongly affected by the start date of the 10-year trend, determined typically by factors such as policy development or funding availability that are unrelated to the population dynamics of the taxa being assessed.

The difficulty of detecting underlying declines from natural population fluctuations in short-term butterfly trends has been recognised previously (e.g. van Strien et al. 1997). Furthermore, the impact of temporal scale of trend measurement has been noted in comparisons of Red Lists produced using long-term versus 10-year trends (de Iongh and Bal 2007; van Swaay et al. 2011), and authors have recommended or developed adjustments to assessments under IUCN Criterion A to take long-term trends into consideration (Maes et al. 2012). In response, current IUCN guidance acknowledges this issue and sanctions optional use of data over a longer period to model population decline, especially for species with highly variable population levels, while still requiring trends to be measured over the most recent 10 years (IUCN 2017). Nevertheless, the 10 -year rule remains fundamental to IUCN Criterion A and practitioners can continue to assess the threat levels of short-lived species based on just a decade of population data.

The purpose of this study is to highlight, from a practitioner's perspective, problems with the application of 
10-year population trends in the Red Listing of insects and to seek further advice from IUCN. Specifically, we quantify, for the first time, the direct implications of high levels of inter-annual population variation (process errors) on Red List classification under IUCN Criterion A. Our assessment of two United Kingdom (UK) insect taxa for which standardised population monitoring data are available, butterflies and macro-moths, is then used to consider whether the 10-year rule is appropriate for such taxa.

\section{Methods and results}

We consider two case studies using UK insect population data for butterflies and macro-moths derived from long-term $(40+$ years) monitoring schemes to assess the impact of species' population variability on Red Listing using IUCN Criterion A. Although butterflies and moths are closely related taxa in the Order Lepidoptera, considering them as separate case studies is appropriate and informative as the monitoring schemes and datasets for each are independent and utilise different methodologies (fixed-width line counts for butterflies and point counts using light-traps for macro-moths) to sample diurnal and nocturnal insect communities respectively. In addition, long-running time series of standardised abundance for insect taxa are rare in the UK and globally; the only other insect taxon for which data are available over a comparable duration in the UK are aphids (Order Hemiptera, Superfamily Aphidoidea), although the geographical coverage is much less extensive (Thomas 2005).

We also varied two aspects of the assessment method in each case study: standardisation of time periods across species and the use of population trends with or without statistical significance. First, in the butterfly case study, the 10 -year periods being compared were standardised (i.e. they started in the same year for each species), whereas in the macro-moth case study, the 10-year time periods varied between species according to data availability. Second, butterfly population trends were assessed against the IUCN threat category thresholds irrespective of whether the trends were statistically significant, while in the macro-moth study only statistically significant population trends were used in the assessment. These alternatives were used to represent the range of different approaches likely to be employed by practitioners undertaking Red List assessment depending on the form and availability of data.

It should be noted that the case studies do not represent the application of a complete Red List process, but are indicative assessments of the potential impact of one IUCN criterion on the outcome. A full Red List procedure would utilise other criteria based on geographical range and population size (depending on data availability) and also, when carried out at a regional level, an important additional consideration is the potential for the extinction risk of a taxon to be influenced by movement of individuals into or out of the region being assessed (IUCN 2012). However, our consideration of Criterion A in isolation is relevant because threatened Red List status is conferred under the precautionary principleas long as a taxon meets the threshold for a single criterion then it can be classified as threatened. Thus, false positive assessments under Criterion A (or any criterion) could exert substantial influence over completed Red Lists.

\section{Case study 1: UK butterflies}

We considered the impact of arbitrary start date on the Red List outcomes for UK butterflies based on published 10-year population trends derived by linear regression from the UK Butterfly Monitoring Scheme (UKBMS) over 6 consecutive years (http://www.ukbms.org; Pollard and Yates 1993; Roy et al. 2015). The standardised, annual monitoring of butterfly abundance by the UKBMS at over 1000 sites generates robust population data used by the Government to assess biodiversity trends (Brereton et al. 2011; Eaton et al. 2015). Despite low observation error, 10-year UKBMS population trends for many species fluctuate considerably from year to year, reflecting stochastic environmental variation (process error) (Online Resource 1). The 10-year population trends for each species were assessed against the IUCN Criterion A2 thresholds (A2 being for population trends where the reduction or its causes may not have ceased or may not be understood or may not be reversible) and species allocated to threat categories accordingly. Trend values were utilised in the assessment irrespective of their statistical significance (in contrast to the macro-moth case study). Thus, six classifications were produced using population trends for six 10 -year periods, each starting 1 year after the previous one (i.e. 2001-2010, 2002-2011, 2003-2012, 2004-2013, 2005-2014 and 2006-2015). In addition, the median, lower and upper quartile population trends were calculated for each species from the six 10-year trend values and these were also assessed against IUCN Criterion A2.

Fifty-four species (of the 59 resident or common migrant butterfly species present in the UK) had UKBMS 10-year population trends for all six periods considered. There was considerable variation in the total number of species qualifying for Red List categories between classifications and for individual species across classifications. An average of 18.5 species met the IUCN Criterion A2 thresholds for threatened status (i.e. Critically Endangered $\geq 80 \%$ population decrease, Endangered $\geq 50 \%$ decrease or Vulnerable $\geq 30 \%$ decrease) per period, but the number of species qualifying ranged from 13 (24\% of species) to 29 (54\% of species) (Table 1). Twenty species (37\% of the total) were consistently classified across the six different time periods (i.e. they either always ( 3 species) or never (17 species) qualified as 
Table 1 Number of UK butterfly species (of 54 species assessed) meeting Red List threat thresholds under IUCN Criterion A2 (reduction in population size) on basis of 10-year UKBMS population

\begin{tabular}{lccccccccc}
\hline & $2001-2010$ & $2002-2011$ & $2003-2012$ & $2004-2013$ & $2005-2014$ & $2006-2015$ & Median & Lower Qrt & Upper Qrt \\
\hline CR & 2 & 4 & 5 & 5 & 2 & 2 & 2 & 6 & 1 \\
EN & 10 & 8 & 14 & 11 & 7 & 4 & 11 & 12 & 4 \\
VU & 6 & 3 & 10 & 4 & 7 & 7 & 5 & 7 & 3 \\
Total & 18 & 15 & 29 & 20 & 16 & 13 & 18 & 25 & 8 \\
\hline
\end{tabular}

$C R$ critically endangered (decrease $\geq 80 \%$ ), $E N$ endangered (decrease $\geq 50 \%$ ), $V U$ vulnerable (decrease $\geq 30 \%$ ). These classifications do not represent the final outcomes of a full Red List process

threatened), but 34 species (63\%) qualified as threatened in some periods and not others (Table 2). Removing the three common migratory species from the sample had no qualitative effect on the overall pattern.

Using the median population change value over the six 10-year periods for the Red List assessment produced 18 threatened species, the lower quartile trend value led to 25 threatened species and the upper quartile trend just 8 species (Table 1 ). The threat category assigned to a particular species frequently differed between the median, lower and upper quartile values (Table 2).

\section{Case study 2: UK macro-moths}

A second case study, using population data for $431 \mathrm{UK}$ macro-moths (hereafter "moths"), was undertaken to assess the wider applicability of the results for butterflies.

Monitoring of adult moth numbers has been carried out across the UK since 1968, as part of the Rothamsted Insect Survey (RIS) run by Rothamsted Research (http://www.rotha msted.ac.uk/insect-survey). Standardised light-traps operate at approximately 80-100 sites annually, on every night of the year and all moths attracted into the traps are retained for identification by professional staff or expert volunteers (Conrad et al. 2004). The data have been used to assess longterm change in moth biodiversity, including as part of official Government indicators (Conrad et al. 2006; Eaton et al. 2015; Burns et al. 2018).

For this case study, we present a preliminary analysis of RIS abundance data using the Generalized Abundance Index (GAI) approach (Dennis et al. 2016). RIS count data were extracted for UK resident moth species in the families Hepialidae, Cossidae, Sesiidae, Limacodidae, Zygaenidae, Drepanidae, Lasiocampidae, Endromidae, Saturniidae, Sphingidae, Geometridae, Notodontidae, Erebidae, Noctuidae and Nolidae (Agassiz et al. 2013). Species that occur in the UK only as immigrants were excluded. Daily species count data for the full RIS time series (1960-2015) were analysed using the GAI method and trends assessed using linear regression. The data were not filtered prior to analysis, but post hoc tests on the GAI for the entire time series of data for each species were used to identify statistically unreliable models. Species were excluded from the case study where the results contained indices for less than 10 years and/or where the number of years with missing indices was greater than $30 \%$ of the total series. In addition, the annual index values and their standard errors were assessed and species exhibiting extreme indices (indices $<0$ or $>4$ ) or exceptionally large standard errors (standard error $>1$ ) were also excluded from the case study.

Having excluded species that did not meet the minimum statistical requirements, a series of five, overlapping 10-year population trends were calculated for the remaining species. First, in keeping with the IUCN 10-year rule, GAI values for the most recent 10 years available for each moth species were used to derive a population trend by fitting linear regressions. The key parameters (e.g. slope, intercept, statistical significance) of each of these linear models were stored, and measures of annual growth rate and proportional change over the 10-year time period were calculated from these parameters. For the majority of species the most recent 10-year period was 2006-2015. However, as data availability varied from species to species, e.g. because rapidly declining species become so scarce that they are no longer caught at all in the RIS monitoring network, the start/end year of this most recent 10-year period was not the same for all species.

Next, this process was repeated four times for every moth species, on each occasion starting the 10-year period one year earlier. Only the GAI values for each 10-year period were used to calculate the population trend in each instance. This resulted in five 10-year population trends per species, each trend lagged by 1 year: $t$ (the most recent 10 years), $t-1$, $\mathrm{t}-2, \mathrm{t}-3$ and $\mathrm{t}-4$. For the majority of species, the five trends covered the periods 2006-2015, 2005-2014, 2004-2013, 2003-2012 and 2002-2011, but some extended back into the 1990 s and, in one case, the 1980s. For each time period, 10-year species population trends that were statistically significant at $\mathrm{p}<0.05$ were then assessed against IUCN Criterion A2 thresholds to provide a threat (extinction risk) classification.

Population trends for a total of 431 moth species, which had statistically reliable long-term GAI models, were 
Journal of Insect Conservation (2019) 23:269-278

273

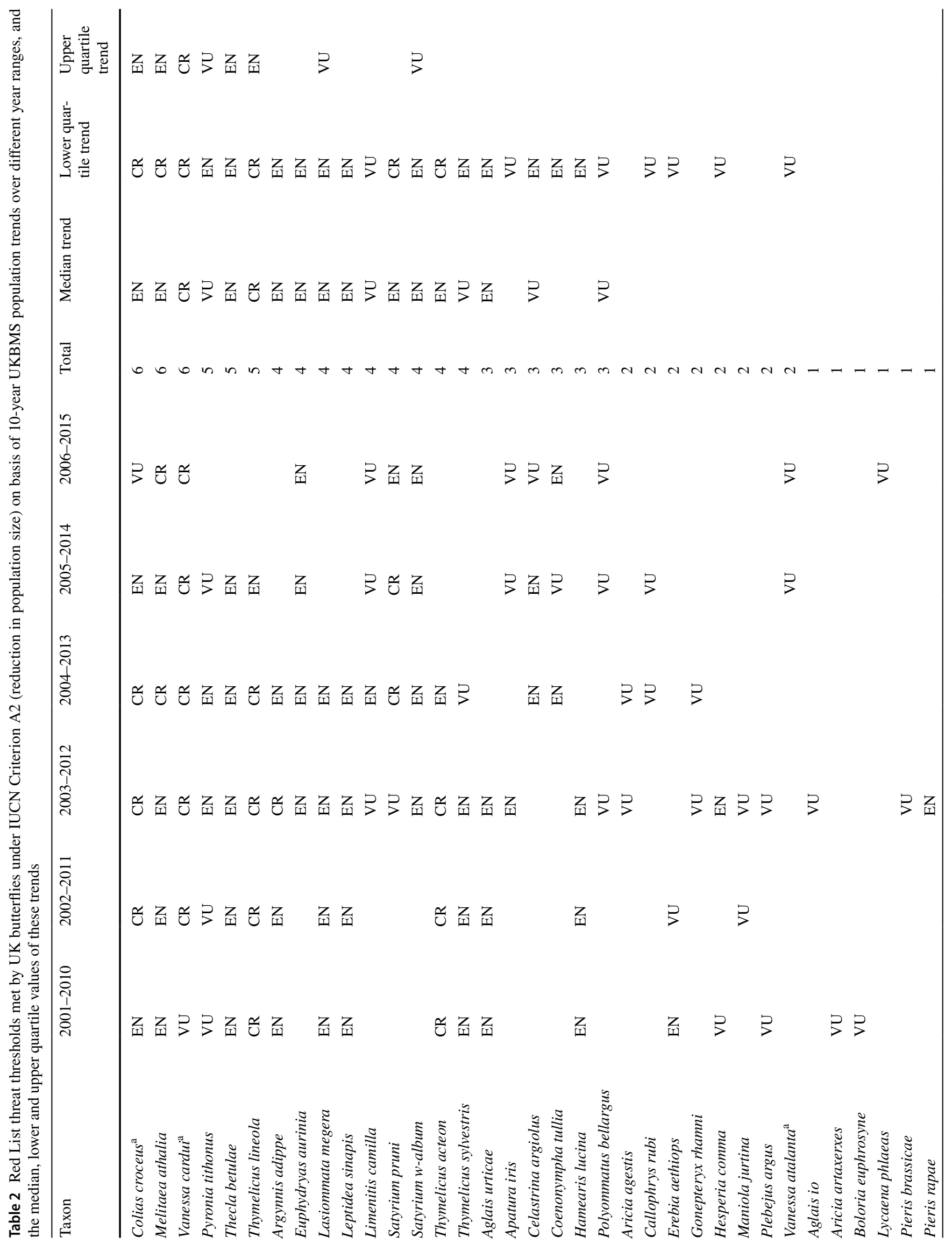

Springer 


$$
\mathbb{E}
$$


assessed across five overlapping 10-year time periods (Online Resource 2). 109 species (25\% of the total) had statistically significant 10 -year population trends that met IUCN Criterion A2 thresholds for Red List threat categories (i.e. Critically Endangered $\geq 80 \%$ population decrease, Endangered $\geq 50 \%$ decrease or Vulnerable $\geq 30 \%$ decrease) in at least one of the five time periods. The remaining 322 species ( $75 \%$ of the total) did not meet these conditions in any of the five 10-year periods. However, of the 109 species that qualified as threatened, only five (4.6\%) did so in all five of the time periods; the remaining 104 moth species were variable, qualifying for the Red List in some time periods but not in others, despite the fact that the five time periods were offset by only one year in each case.

The number of moths qualifying under Criterion A2 varied considerably between the time periods (Table 3). Most dramatically, the difference of a single year between period $\mathrm{t}-3$ and $\mathrm{t}-4$ reduced the number of qualifying species from $62(14 \%$ of the total number of species assessed) to just 20 (5\%).

While appropriate for use in this case study and for demonstrating the variation in trend magnitude from year to year, it should be noted that this is a preliminary analysis of RIS data and the proportional change values over time for individual species may differ when a more detailed analysis is carried out.

\section{Discussion}

The case studies using UK butterfly and macro-moth population time series revealed large discrepancies between Criterion A Red List classifications produced using trends that differed by just a single year. For individual species, the temporal patterns of Red List qualification might reflect genuinely improving or deteriorating levels of extinction risk. On the other hand, and as indicated by the dynamic nature of many species population trends between years (Online Resources 1 and 2), patterns may be artefacts of process

Table 3 Number of UK macro-moth species (of 431 species assessed) meeting Red List threat thresholds under IUCN Criterion A2 (reduction in population size) on the basis of preliminary 10-year RIS population trends representing the most recent 10 -year period $(\mathrm{t})$ and preceding 10-year periods each starting one year earlier than the previous $(\mathrm{t}-1, \mathrm{t}-2, \mathrm{t}-3, \mathrm{t}-4)$. These classifications do not represent the final outcomes of a full Red List process

\begin{tabular}{lrrrrr}
\hline & $\mathrm{t}$ & $\mathrm{t}-1$ & $\mathrm{t}-2$ & $\mathrm{t}-3$ & $\mathrm{t}-4$ \\
\hline Critically endangered & 14 & 17 & 13 & 13 & 4 \\
Endangered & 27 & 24 & 35 & 37 & 11 \\
Vulnerable & 5 & 5 & 9 & 12 & 5 \\
Total & 46 & 46 & 57 & 62 & 20 \\
\hline
\end{tabular}

errors driven by environmental (particularly climatic) variability. Whatever the specific cause of the intra-species variation, the application of the 10-year rule, and specifically the requirement for the population trend to be measured over the most recent 10 years, leads, in our opinion, to a scientifically unacceptable dependency of the Red List classification outcome on the year in which the process is undertaken.

The use and misuse of IUCN Red List criteria has been considered frequently in the literature (Eaton et al. 2005; Akçakaya et al. 2006; Collen et al. 2016), but the specific issue concerning the use of short-term (the most recent 10 years or three generations) population trends to classify insect taxa under Criterion A has not been addressed. Many insect species naturally undergo highly variable and erratic population dynamics, due to environmental variation (Williams 1961) or density-dependence effects (Hanski 1990), and, as illustrated in the case studies using UK butterflies and moths, this may impact significantly on the Red List classifications.

Studies using vertebrate population data have concluded that longer time series can improve the assessment of extinction risk under Criterion $\mathrm{A}$, and practitioners undertaking Red Listing of butterflies have highlighted the same issue (van Swaay et al. 2011; Maes et al. 2012). Indeed the current IUCN guidelines reflect this, suggesting that using data from a longer time period to fit a statistical model of population decline may be preferable for species that have widely fluctuating or oscillating population dynamics (in Sect. 4.5.1, IUCN 2017). Nevertheless, the IUCN guidelines go on to stress that having fitted the model, the proportional decline should still be calculated over the most recent 10 years or three generations, as per the 10-year rule. In light of our results, we do not consider this guidance to be sufficient. It is optional, dependent on the availability of long-term data and relies on practitioners being familiar with the detailed IUCN guidance. Even if applied, the requirement to calculate change over the most recent 10 years is unlikely to ameliorate the problem illustrated by our case studies, as high levels of inter-annual population variability within the 10 -year period are still likely to strongly skew trends and therefore Red List assessments. More fundamentally, the 10-year rule remains the basis of IUCN Criterion A and can be used to determine the extinction risk of species without use of longer-term data. Our results, quantifying the impacts of 10-year trend start year on the number and identity of species meeting Red List thresholds, suggest that this is inappropriate for UK butterflies and macro-moths and potentially for many other insect and invertebrate taxa around the world.

An obvious solution to the problem is to measure population trends over a longer period of time rather than the last 10 years. Linear trends over the $40+$ year time series available for both UK butterflies and moths dampen the effects of annual variation, providing a more robust assessment of 
population change. From such long-term population trends, annual rates of change can be used to calculate a 10 -year trend for each species that can be assessed against the IUCN Criterion A thresholds. The important distinction is that this is a population change measured over an average 10-year period of a longer time interval, rather than being measured over the most recent 10 years.

This approach brings other benefits too. IUCN guidance explicitly warns against interpreting the downward phase of population cycles as a reduction under Criterion A (Sect. 4.5, IUCN 2017). While there are well-established cases of population periodicity in moths (e.g. Berryman 1996; Johnson et al. 2006; Bell et al. 2012), for most species it is unclear whether populations are truly cyclical or simply erratic, making it difficult to apply the IUCN guidance. Trends derived from a long-term time series will be less prone to misinterpretation and misclassification caused by unrecognised population cyclicity. In addition, if practitioners determine that only statistically significant population trends should be used to assign species to Red List threat categories, trends calculated over just the most recent 10 years are unlikely to attain significance, when populations are naturally variable, even if reductions (or increases) are very large, as a result of the small number of data points.

Despite all of these benefits, the key problem with adopting such an approach for Red Listing is that the IUCN guidelines are clear that Criterion A should represent the recent population trend of a taxon and not take account of historical declines. Indeed the 10-year rule is specifically there to ensure that species that have undergone major declines in the past, but are currently stable or recovering, are not classified as threatened under the IUCN Red List process (unless there is sufficient evidence of future threats to support a projected decline that meets threshold levels) (Sects. 5.4 and 5.5, IUCN 2017).

As a compromise, which avoids the spurious variability of the 10-year rule yet embraces the spirit of reflecting recent population decline, we propose a two-step process to the implementation of IUCN Criterion A with insect population trends. First, long-term data are used to derive an average 10-year trend over the full time series, which is then assessed against the IUCN quantitative thresholds to produce a provisional threat classification for each species. Second, a population trend derived just from the last 10 years of data is calculated for each species and used to adjust the provisional threat classification using expert judgement. Thus, the threat status of species with a long-term population decline but recent stability or recovery would be downgraded, while that of species with both long-term and recent declines would be maintained, or even be increased if the recent trend shows an increasing rate of population reduction. As with all elements of the Red Listing process, it would be essential to document the basis for upgrading or downgrading the threat category of each species to ensure transparency.

An alternative approach to adjusting the classification produced by Criterion A was implemented by Maes et al. (2012) when applying the IUCN criteria to butterflies in Flanders (Belgium). They calculated 10-year rates of change (from occurrence rather than abundance data) and applied the IUCN Criterion A thresholds to produce an initial classification for each species. They then upgraded species by one Red List category if they had shown $>50 \%$ historical distribution decline over a longer time period (c.30 years).

The IUCN Red List process is an important force in biodiversity conservation and has been successfully applied at global, regional and national levels to a wide range of taxa, including insects and other invertebrates (Collen et al. 2012). This has been aided in recent years by the development of new statistical techniques to extract reliable trends from species occurrence data (Isaac et al. 2014; Maes et al. 2015; Dennis et al. 2017). Long- and short-term temporal trends can now be derived from annual indices generated by occupancy modelling (Burns et al. 2018) and could be used with Criterion A to facilitate Red List assessment of many more invertebrate taxa in many more countries and regions. To our knowledge, the sensitivity of occupancy trends to interannual variability has not been examined and this should be a focus of further research prior to the use of such trends under the 10-year rule in Red List assessment for insects.

Robust population monitoring remains the gold standard, however, for measuring biodiversity change (Roy et al. 2007; Morecroft et al. 2009) and the geographical and taxonomic extent of such schemes for insects continues to expand (van Swaay et al. 2008; Carvell et al. 2018; Matechou et al. 2018). Where available, population monitoring data should be utilised in Red List assessments, yet the natural variability of insect populations presents a dilemma for conservation practitioners in applying the Red List '10-year rule'. Given the variability illustrated here with case studies on UK butterfly and macro-moth populations, practitioners should be extremely wary of assigning extinction risk to insects based on only the last 10 years of population data as per IUCN Criterion A. Our examples suggest that longer time series of data are required to produce a robust assessment, but trends measured over a long time period are likely to be less indicative of the current extinction risk of a species. While we have proposed one possible compromise solution to ameliorate this issue, and other practitioners may adopt other approaches, further consideration and advice from IUCN on the application of Criterion A for species with high process errors would be very welcome.

Acknowledgements We would like to thank all of the volunteers involved in gathering the UK butterfly and moth population data. We are grateful to Dr Nick Isaac and two anonymous reviewers for helpful 
comments on earlier drafts of this paper. The Rothamsted Insect Survey, a National Capability, is funded by the Biotechnology and Biological Sciences Research Council under the Core Capability Grant $\mathrm{BBS} / \mathrm{E} / \mathrm{C} / 000 \mathrm{~J} 0200$. We are grateful to collaborators and staff who have contributed to the Rothamsted Insect Survey light-trap network since the 1960s. The UK Butterfly Monitoring Scheme is operated by the Centre for Ecology \& Hydrology, Butterfly Conservation and the British Trust for Ornithology, and funded by a multi-agency consortium including the Joint Nature Conservation Committee, Forestry Commission, Natural England, the Natural Environment Research Council, Natural Resources Wales and Scottish Natural Heritage.

\section{Compliance with ethical standards}

Conflict of interest The authors declare that they have no conflict of interest.

Open Access This article is distributed under the terms of the Creative Commons Attribution 4.0 International License (http://creativeco mmons.org/licenses/by/4.0/), which permits unrestricted use, distribution, and reproduction in any medium, provided you give appropriate credit to the original author(s) and the source, provide a link to the Creative Commons license, and indicate if changes were made.

\section{References}

Agassiz DJL, Beavan SD, Heckford RJ (2013) A checklist of the Lepidoptera of the British Isles. Royal Entomological Society, St Albans

Akçakaya HR, Butchart SHM, Mace GM, Stuart SN, Hilton-Taylor C (2006) Use and misuse of the IUCN Red List Criteria in projecting climate change impacts on biodiversity. Glob Change Biol 12:2037-2043

Azam CS, Gigot G, Witte I, Schatz B (2016) National and subnational Red Lists in European and Mediterranean countries: current state and use for conservation. Endang Species Res 30:255-266

Bell JR, Burkness EC, Milne AE, Onstad DW, Abrahamson M, Hamilton KL, Hutchison WD (2012) Putting the brakes on a cycle: bottom-up effects damp cycle amplitude. Ecol Lett 15:310-318

Berryman AA (1996) What causes population cycles of forest Lepidoptera? Trends Ecol Evol 11:28-32

Brereton T, Roy DB, Middlebrook I, Botham M, Warren M (2011) The development of butterfly indicators in the United Kingdom and assessments in 2010. J Insect Conserv 15:139-151

Burns F, Eaton MA, Hayhow DB, Outhwaite CL, Al Fulaij N, August TA, Boughey KL, Brereton T, Brown A, Bullock DJ, Gent T, Haysom KA, Isaac NJB, Johns DG, Macadam CR, Mathews F, Noble DG, Powney GD, Sims DW, Smart SM, Stroh P, Walker KJ, Webb JR, Webb TJ, Gregory RD (2018) An assessment of the state of nature in the United Kingdom: a review of findings, methods and impact. Ecol Indic 94:226-236

Cardoso P, Borges PAV, Triantis KA, Ferrández MA, Martín JL (2011) Adapting the IUCN Red List criteria for invertebrates. Biol Conserv 144:2432-2440

Carvell C, Pollinator Monitoring and Research Partnership (2018) Establishing a UK Pollinator Monitoring and Research Partnership progress report January 2018. Centre for Ecology \& Hydrology and PMRP. https://www.ceh.ac.uk/sites/default/files/Polli natorMonitoringandResearchPartnership_Progressreport_Janua ry 2018.pdf. Accessed 22 September 2018
Collen B, Böhm M, Kemp R, Baillie JEM (2012) Spineless: status and trends of the world's invertebrates. Zoological Society of London, London

Collen B, Dulvy NK, Gaston KJ, Gärdenfors U, Keith DA, Punt AE, Regan HM, Böhm M, Hedges S, Seddon M, Butchart SHM, Hilton-Taylor C, Hoffmann M, Bachman SP, Akçakaya HR (2016) Clarifying misconceptions of extinction risk assessment with the IUCN Red List. Biol Lett 12:20150843

Connors BM, Cooper AB, Peterman RM, Dulvy NK (2014) The false classification of extinction risk in noisy environments. Proc $\mathrm{R}$ Soc B 281:20132935

Conrad KF, Woiwod IP, Parsons M, Fox R, Warren M (2004) Longterm population trends in widespread British moths. J Insect Conserv 8:119-136

Conrad KF, Warren M, Fox R, Parsons M, Woiwod IP (2006) Rapid declines of common, widespread British moths provide evidence of an insect biodiversity crisis. Biol Conserv 132:279-291

d'Eon-Eggertson F, Dulvy NK, Peterman RM (2015) Reliable identification of declining populations in an uncertain world. Conserv Lett 8:86-96

de Iongh HH, Bal D (2007) Harmonization of Red Lists in Europe: some lessons learned in the Netherlands when applying the new IUCN Red List categories and criteria version 3.1. Endanger Species Res 3:53-60

Dennis EB, Morgan BJT, Freeman SN, Brereton TM, Roy DB (2016) A generalised abundance index for seasonal invertebrates. Biometrics 72:1305-1314

Dennis EB, Morgan BJT, Freeman SN, Ridout MS, Brereton TM, Fox R, Powney GD, Roy DB (2017) Efficient occupancy model-fitting for extensive citizen-science data. PLoS ONE 12:e0174433

Dunn EH (2002) Using decline in bird populations to identify needs for conservation action. Conserv Biol 16:1632-1637

Eaton MA, Gregory RD, Noble DG, Robinson JA, Hughes J, Procter D, Brown AF, Gibbons DW (2005) Regional IUCN Red Listing: the process as applied to birds in the United Kingdom. Conserv Biol 19:1557-1570

Eaton MA, Burns F, Isaac NJB, Gregory RD, August TA, Barlow KE, Brereton T, Brooks DR, Al Fulaij N, Haysom KA, Noble DG, Outhwaite C, Powney GD, Procter D, Williams J (2015) The priority species indicator: measuring the trends in threatened species in the UK. Biodiversity 16:108-119

Gaston KJ, Fuller RA (2008) Commonness, population depletion and conservation biology. Trends Ecol Evol 23:14-19

Hanski I (1990) Density dependence, regulation and variability in animal populations. Phil Trans R Soc B 330:141-150

Hoffmann M, Brooks TM, Fonseca GAB, Gascon C, Hawkins AFA, James RE, Langhammer P, Mittermeier RA, Pilgrim JD, Rodrigues ASL, Silva JMC (2008) Conservation planning and the IUCN Red List. Endanger Species Res 6:113-125

Isaac NJB, van Strien AJ, August TA, de Zeeuw MP, Roy DB (2014) Statistics for citizen science: extracting signals of change from noisy ecological data. Methods Ecol Evol 5:1052-1060

IUCN (2001) IUCN Red List Categories and Criteria: Version 3.1. IUCN Species Survival Commission, Gland

IUCN (2012) Guidelines for application of IUCN Red List criteria at regional and national levels: Version 4.0. IUCN, Gland

IUCN Standards and Petitions Subcommittee (2017) Guidelines for using the IUCN Red List categories and criteria. Version 13. IUCN, Gland

Johnson DM, Liebhold AM, Bjørnstad ON (2006) Geographical variation in the periodicity of gypsy moth outbreaks. Ecography 29:367-374

Keith D, Akcakaya HR, Butchart SHM, Collen B, Dulvy NK, Holmes EE, Hutchings JA (2015) Temporal correlations in population 
trends: conservation implications from time-series analysis of diverse animal taxa. Biol Conserv 192:247-257

Mace GM, Collar NJ, Gaston KJ, Hilton-Taylor C, Akçakaya HR, Leader-Williams N, Milner-Gulland EJ, Stuart SN (2008) Quantification of extinction risk: International Union for the Conservation of Nature's (IUCN) system for classifying threatened species. Conserv Biol 22:1424-1442

Maes D, Vanreusel W, Jacobs I, Berwaerts K, Van Dyck H (2012) Applying IUCN Red List criteria at a small regional level: a test case with butterflies in Flanders (north Belgium). Biol Conserv 145:258-266

Maes D, Isaac NJB, Harrower CA, Collen B, van Strien AJ, Roy DB (2015) The use of opportunistic data for IUCN Red List assessments. Biol J Linn Soc 115:690-706

Matechou E, Freeman SN, Comont R (2018) Caste-specific demography and phenology in bumblebees: modelling BeeWalk data. J Agric Biol Environ Stat 23:427-445

McCain C, Szewczyk T, Bracy Knight K (2016) Population variability complicates the accurate detection of climate change responses. Glob Change Biol 22:2081-2093

Miller RM, Rodríguez JP, Aniskowicz-Fowler T, Bambaradeniya C, Boles R, Eaton MA, Gärdenfors U, Keller V, Molur S, Walker S, Pollock C (2007) National threatened species listing based on IUCN criteria and regional guidelines: current status and future perspectives. Conserv Biol 21:684-696

Mills SC, Oliver TH, Bradbury RB, Gregory RD, Brereton T, Kühn E, Kuussaari M, Musche M, Roy DB, Schmucki R, Stefanescu C, van Swaay C, Evans KL (2017) European butterfly populations vary in sensitivity to weather across their geographical ranges. Glob Ecol Biogeogr 26:1374-1385

Morecroft MD, Bealey CE, Beaumont DA, Benham S, Brooks DR, Burt TP, Critchley CNR, Dick J, Littlewood NA, Monteith DT, Scott WA, Smith RI, Walmsley C, Watson H (2009) The UK Environmental Change Network: Emerging trends in the composition of plant and animal communities and the physical environment. Biol Conserv 142:2814-2832

Oliver TH, Stefanescu C, Páramo F, Brereton T, Roy DB (2014) Latitudinal gradients in butterfly population variability are influenced by landscape heterogeneity. Ecography 37:863-871

Oliver TH, Marshall HH, Morecroft MD, Brereton T, Prudhomme C, Huntingford C (2015) Interacting effects of climate change and habitat fragmentation on drought-sensitive butterflies. Nat Clim Chang 5:941-945

Palmer G, Platts PJ, Brereton T, Chapman JW, Dytham C, Fox R, Pearce-Higgins JW, Roy DB, Hill JK, Thomas CD (2017) Climate change, climatic variation and extreme biological responses. Phil Trans R Soc B 372:20160144

Pollard E, Yates TJ (1993) Monitoring butterflies for ecology and conservation: the British butterfly monitoring scheme. Chapman \& Hall, London

Porszt EJ, Peterman RM, Dulvy NK, Cooper AB, Irvine JR (2012) Reliability of indicators of decline in abundance. Conserv Biol 26:894-904

Rodrigues ASL, Pilgrim JD, Lamoreux JF, Hoffmann M, Brooks TM (2006) The value of the IUCN Red List for conservation. Trends Ecol Evol 21:71-76

Roy DB, Rothery P, Moss D, Pollard E, Thomas JA (2001) Butterfly numbers and weather: predicting historical trends in abundance and the future effects of climate change. J Anim Ecol 70:201-217

Roy DB, Rothery P, Brereton T (2007) Reduced-effort schemes for monitoring butterfly populations. J Appl Ecol 44:993-1000

Roy DB, Ploquin EF, Randle Z, Risely K, Botham MS, Middlebrook I, Noble D, Cruickshanks K, Freeman SN, Brereton TM (2015) Comparison of trends in butterfly populations between monitoring schemes. J Insect Conserv 19:313-324

Thomas JA (2005) Monitoring change in the abundance and distribution of insects using butterflies and other indicator groups. Phil Trans R Soc B 360:339-357

van Strien AJ, van de Pavert R, Moss D, Yates TJ, van Swaay CAM, Vos P (1997) The statistical power for two butterfly monitoring schemes to detect trends. J Appl Ecol 34:817-828

van Swaay CAM, Nowicki P, Settele J, van Strien AJ (2008) Butterfly monitoring in Europe: methods, applications and perspectives. Biodivers Conserv 17:3455-3469

van Swaay C, Maes D, Collins S, Munguira ML, Šašić M, Settele J, Verovnik R, Warren M, Wiemers M, Wynhoff I, Cuttelod A (2011) Applying IUCN criteria to invertebrates: How red is the Red List of European butterflies? Biol Conserv 144:470-478

White ER (2018) Minimum time required to detect population trends: the need for long-term monitoring programs. BioScience. https:// doi.org/10.1093/biosci/biy144

Williams CB (1961) Studies in the effect of weather conditions on the activity and abundance of insect populations. Phil Trans R Soc B 244:331-378

Wilson HB, Kendall BE, Possingham HP (2011) Variability in population abundance and the classification of extinction risk. Conserv Biol 25:747-757

Winfree R, Fox JW, Williams NM, Reilly JR, Cariveau DP (2015) Abundance of common species, not species richness, drives delivery of a real-world ecosystem service. Ecol Lett 18:626-635 